\title{
The Growing Importance Of Operating Employees And Keys To Developing Effective Training Options
}

Dave McMahon, (dave.mcmahon@pepperdine.edu), Pepperdine University Jon C. Carr, (carr@cba.usm.edu), University of Southern Mississippi Stephen A. LeMay, (slemay@ cobilan.msstate.edu), Mississippi State University Jeff Periatt, (jperiatt@mail.aum.edu), Auburn University Montgomery

\begin{abstract}
This study provides a description of the changing role of transportation operating employees, their competencies, job requirements, and training needs. Four key findings for developing effective training options are discussed. The data come from 43 logistics organizations in 20 states using the Common Metric Questionnaire, formal and informal interviews, and a descriptive newsletter.
\end{abstract}

\section{Introduction}

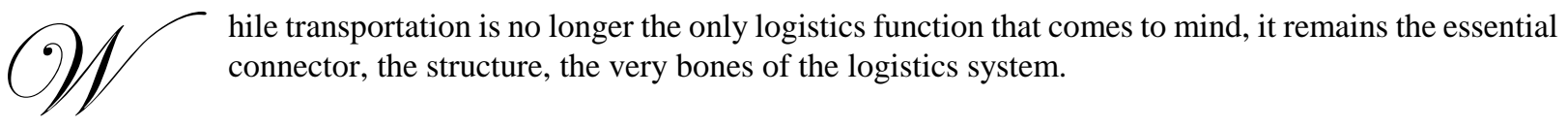

"It almost seems stupid to say it, but we go nowhere without transportation. Warehousing is pointless and, for the most part, so is manufacturing. The goods have to get to markets. Getting them there is transportation. Without transportation, we're down in the riverbed looking for really good rocks to knock off squirrels for dinner. Transportation is the cornerstone of the economy and of modern societies." -Retailing Vice President of Logistics

Human resource problems have seriously affected transportation since deregulation in the late 1970's and early 1980's. Turnover among truck drivers and barge crews, salary tiers for airline pilots, and changes in railroad employment all create controversy and alter the cost structures of the industry in question. Understanding the nature of the work and the changes taking place in transportation employment may help reduce the human resource costs of transportation and create a more effective system.

To better understand the nature of these changes, we undertook a multifunctional, multi-organizational job classification study, the first of its kind. In this study, the researchers took a sample of logistics jobs and established a baseline for evaluating job changes in the future as well as for current job requirements and training needs. Through interviews and additional surveys, we attempted to put the job classification findings into a broader context. This article focuses on the growth and development of a particular job family, transportation operating employees.

The article is divided into two parts. The first part features the methodology used in the study. Next follows a summation of the key findings and takeaways of the study. This is followed by a description of transportation operating employees, their competencies, job requirements, and training needs. The points illustrating the key findings and takeaways are highlighted throughout the text. The second part discusses four key findings to consider when developing a training approach followed by a conclusion. 


\section{Methodology}

To gather data, the Common Metric Questionnaire (CMQ), a descriptive survey of logistics human resources practice, was used along with formal and informal interviews. From 43 logistics organizations, 632 responses to the Common Metric Questionnaire (CMQ) were received. The sample was a selected convenience sample. The 43 organizations included manufacturers, asset-based third parties, non-asset-based third parties, retailers, and financial institutions. Companies ranged in size from 15 to more than 100,000 employees. The researchers visited 65 sites in 20 states to gather data. They also conducted 35 formal interviews with top managers and more than 200 informal interviews with managers, supervisors, and operating employees. In addition, 192 companies responded to the descriptive newsletter sent to them by the researchers.

\section{CMQ-Description and Administration}

The CMQ boasts a validation database of over 100,000 observations on 8000 job families. The CMQ is comprised of more than 3000 items, although each subject was likely to address only a subset of that total. Responses to the CMQ reveal critical knowledge and skills for job performance, the frequency with which these skills are used, and the ways in which skills and knowledge were obtained. The responses also show job activities, such as attending meetings, lifting heavy objects, and interacting with people inside and outside the firm. These results fall into four domains, 80 dimensions, and 17 second-order factors. This detailed questionnaire helps determine competencies, job requirements, and training needs for each job family in the analysis. Questionnaire items also cover demographics, job basics, and knowledge requirements.

Data Analysis

The data were analyzed using the Common Metric System (CMS), a proprietary system coupled with the CMQ. CMS clusters the data into job families based on the responses the researchers selected for inclusion in the analysis. Initially, seven a-priori job families or clusters were identified: senior management, logistics information systems, warehousing, material and inventory control, transportation, purchasing, and customer service. Three researchers assigned each response to these fields, with a first-time classification interrater correlation of .95. Researchers then worked with the exception responses to achieve consensus, ultimately producing an inter-rater correlation of 1.00 .

The pre-classified responses were then included in a cluster analysis by job family. A job was retained in a classification only if its joint correlation with the other responses was .70 or higher. In this way, researchers were able to classify all 632 observations into 22 job families: one for broad responsibility senior management, two for logistics information systems; six for warehousing, four for transportation, two for purchasing, three for customer service, and four for material and inventory control.

\section{Motor Carrier Operating Employees Job Description}

Trucking dominates this discussion; however one must bear in mind that motor carrier operating employees not only drive trucks, they also operate trains, pilot ships, and fly planes. They also coordinate the movement of goods through the logistics system. Far from simply operating the vehicles, motor carrier operating employees increasingly direct their own work.(1)

The analysis of the survey data placed dispatchers and truck drivers in the same job family. While the two jobs differ in the equipment operated and the amount of time personnel spend on the road, they differ little in interpersonal interactions, decision-making, and work context. Dispatchers and drivers also share a common body of required knowledge. In short, they do much the same job, one group from the office, the other from the cab of the truck. This clustering reflects the trend toward driver self-dispatch on many loads, most commonly from the firm's web site.(1) 


\section{Key Findings and Takeaways for Transportation Operating Employees}

Points in the text supporting each key finding are tagged with a number in parentheses, e.g (1).

1 Transportation tends toward flatter organizations with increasing responsibility placed on operating employees. In trucking, dispatchers and drivers perform many of the same tasks, one from the truck cab, the other from the terminal or home office. This trend is driven by information technology.

2 Since motor carrier operating employees spend much of their work time away from the firm, communication technology is especially important. Training for operating employees should extend beyond equipment operation to its effective use. When people with poor communications skills use communications technology, poor communication simply takes place more quickly over a longer distance.

3 Motor carrier operating employees require equipment training, licensing, and certification, but also training in information technology, satellite communication, and interpersonal skills.

4 Motor carrier operating employees deal with customers' and suppliers' warehousing employees-contact that can improve or detract from these valuable relationships.

$5 \quad$ Loaders and operating employees contact customers more often than any other job families except customer service, a fact that suggests training needs in sales and customer relations. Such training would also encourage retention

Consequently, driving is good preparation for dispatching-and vice versa. These employees operate communications equipment, including telephones, satellite and other truck- born devices, and computer systems. Dispatchers as well as drivers must also understand vehicle operation intimately. When one side of the communication fails to grasp the operating situation, problems arise that may disrupt customer service, increase employee stress, and decrease employee retention. (2)

"The dispatcher told the driver he could pass under the bridge. (The mapping program) said the clearance was 14' 4". The truck was 14' 2" clearance or something like that. Anyway, by the numbers on the truck and the numbers in (the mapping program), the truck should have been able to go under. The driver said he couldn't do it, because the sign on the bridge said 13' 9". The driver didn't think he could get under, even by letting air out of the tires. They argued for quite awhile, but the dispatcher insisted. The driver got angrier by the minute. Finally, he said, "All right, I'll take it under there, but you ----, you better remember I told you it wouldn't go." About a foot under the bridge, the top of the trailer started to scrape, but the driver kept powering up and eventually pulled it through. It peeled back the top of the trailer, popped all the welds at the corners, so, yeah, that truck you saw driving down the road belonged to (my former company). It was quite a sight, with the sides sort of flopping out and the top bouncing up and down. It looked like an open sardine can." -Former Trucking Operations Manager, on an event witnessed by one of the researchers

While one aspect of the job is operating and understanding equipment, the other is interpersonal-interacting constantly with customers, suppliers, the office, other drivers, and other transportation employees. The on-board technology can increase the amount and effectiveness of communications, but only if it is used well. It does not always improve communications, because some dispatchers and drivers fail to use all of its capabilities. When dispatchers send the message "Call dispatch," the system adds little value.(2)

When operating employees are on the road, they experience horrendous stress. Driving 10 hours in heavy expressway traffic puts stress on anyone, but in an 18 wheeler carrying half a million dollars of customer freight, the stress is worse. Even back in the office, the stress is high because the dispatcher feels time pressure from deadlines as much as or more than the drivers.(3)

These employees experience the adventure and poetry of transportation first hand. Vehicle breakdowns, adverse weather, congestion, and accidents may cause problems in the office, but the drivers must react to them firsthand. 
Motor Carrier Operating Employees Competencies

Operate vehicles in keeping with company policy and the law, while satisfying customer requirements and minimizing costs. Laws and regulations restrict vehicle size, weight, speed, and hours of operation. They also restrict the driver's hours, allowable emissions, packaging for some freight, and routes. Loosening these restrictions might allow a firm to serve its customers better, but the restrictions remain, presumably to serve a greater social purpose. Customer requirements may not recognize those restrictions, or transportation organizations may fear that compliance will cost them customers or business. Consequently, some pressure is placed on operating employees to violate laws and regulations to meet customer delivery schedules. Often dispatchers, customer service representatives, or sales representatives over-promise on delivery schedules, thereby creating a quandary for the transportation organization. Based on this research, such behavior constitutes incompetence. Put simply, operating in compliance with laws and regulations is a part of competence. Communicating with customers and helping them to adjust their expectations is another aspect of competent transportation, one usually left to managers.

This competency is complex, but it expresses the essence of the transportation operating employee's job. Failing to operate within the law may subject a firm to fines and open it to liability. The technology that now rapidly improves logistics performance will also improve the performance of regulatory agencies, especially their ability to monitor compliance to performance standards such as speed limits and operating time. (3)

A common reason for failing to operate within company policies is not knowing them, a communications problem. Managers are too often guilty of changing policies that directly affect truck drivers without giving the driver adequate notice. The driver is often on the road when he or she discovers that the company no longer pays for motel rooms until 48 hours into a layover because the policy change took place after the driver left. Operating employees cannot comply with policies they do not know.(2)

Satisfying customer requirements assumes knowing those requirements, a key aspect of the next competency. Such satisfaction also depends on communication between customers, traffic and transportation employees, and drivers. $(2,4)$

Cost minimization implies making good decisions about vehicle maintenance, routing, and operation. Sound decisions often result from good working relationships between dispatchers and drivers. Poor working relationships almost invariably increase costs.

Finally, the central issue in this competence is operating the vehicle. Competence requires understanding the equipment and using it safely and effectively. Given the complexity of most vehicles, such understanding is no small matter.(3)

Use communications technology and interpersonal skills to understand, disseminate, and meet customer needs. Motor carrier operating employees must grasp the immediate needs of clients and customers. When the customer expects a vehicle to arrive, that expectation should be at least possible, if not probable. Staying in contact with the customer is crucial-and truck drivers and dispatchers are in constant contact with customers. They must let operations know what they learn from that contact and operations must listen. Such communication applies in all modes of transportation, but especially in trucking where the contact between transportation employees and customer employees may be personal and frequent. (3)

One director of transportation had the point illustrated for him several years ago:

"We had a driver, Bubba, who worked a retail route into Atlanta. He became so well-liked by the warehouse people at several of our customers, when they saw him pull into the distribution center, they would wave him to the front of the line to unload. When I visited the retailer, I handed the security guard my business card. The guard asked me if I worked for Bubba." -Manufacturing Director of Transportation 

driver:

In another instance, the firm very nearly missed $\$ 20,000$ in revenue because no one could find time to listen to a

The driver walked to a dispatcher's desk, only to be waved away by a dispatcher, who was deep into a phone conversation. The driver moved toward another desk and was waved away again. The process continued until nearly every dispatcher had waved the driver away. The driver turned in slow circles, clearly having something important to say and no one to say it to. An observer, one of two consultants in the firm that day, walked to the driver and said, "You look like you want to tell someone something. Why don't you tell me?"

The driver looked startled, sized up the observer, and said, "It's probably not a big deal, but I just dropped off a load up the street at (a customer's manufacturing plant). They've got fifteen truckloads no one has covered yet. I know we've got a lot of trucks in the yard right now, so I thought we ought to get somebody over there right away." The observer heard the driver out, then told a manager, and several trucks were dispatched immediately. -An event witnessed by one of the researchers

Maintain an understanding of delivery conditions and operating characteristics at customer sites. The more operating employees know about customer locations and customer practices, the more readily they can comply with customer requirements. This knowledge allows operating employees to meet customer expectations quickly, while improving cost performance. Such knowledge also reduces job frustration and contributes to employee retention. (4)

"One problem is having our drivers go into a large customer facility with dozens of trailers. If they haven't been there before, they have a hard time finding the one they're supposed to pull-assuming they can find the facility at all. With new drivers this can cost us two days or more because of missed appointments, or you know, getting there too late and having to lay over for the weekend." -Manufacturing Traffic Manager

Table 1: Motor Carrier Operating Employees Competencies

- Operate vehicles in keeping with company policy and the law, while satisfying customer requirements and
minimizing costs.
Use communications technology and interpersonal skills to understand, disseminate, and meet customer needs.
Maintain an understanding of delivery conditions and operating characteristics at customer sites.

\section{Motor Carrier Operating Employees Job Requirements}

Motor carrier operating employees must know the vehicles they operate, the communications equipment that keeps them linked to the terminal and the customer, basic mathematics, and must possess interpersonal skills. Such expertise includes knowing relevant laws and regulations for the mode of transportation, maintaining self control in stressful situations, and disseminating information through operations about customers, suppliers, and vehicles. Vehicle operation usually requires licensing and certification.

Such are the minimum knowledge and skill requirements for performing these jobs. They are precursors to competence. Putting together the competencies and job requirements leads directly to the analysis of training needs, which are discussed in the next section.

\section{Motor Carrier Operating Employees Training Needs}

Far too often, motor carrier operating employees are trained exclusively in vehicle operation. This leaves to chance-trial and error learning-skills that are central to the performance of their jobs. These crucial abilities include communication skills, stress management, anger management, and knowledge of customer relations techniques. Employees also need to know the customer's operations, delivery conditions, facilities, and networks. $(\mathbf{1 , 2 , 3 , 5 )}$ 


\begin{tabular}{|ll|}
\hline Table 2: & Motor Carrier Operating Employees Job Requirements \\
\hline - & Vehicle operation \\
- & Vehicle inspection \\
- & Vehicle routine maintenance \\
- & Vehicle loading, load balancing \\
- & Licensing and certification \\
- & Telecommunications equipment operation \\
- & Leacommunications equipment troubleshooting \\
- & Customer facilities and networks \\
- & Firms' policies and procedures \\
B & Interpersonal skills \\
\hline
\end{tabular}

Transportation operating jobs will expand in the future, accommodating more and more tasks as technology permits and encourages change. Employees in this field have direct contact with customers, cargo, suppliers, and their own terminal and home offices. They are often in a better position than anyone else to understand customer needs and match them to the firm's capabilities. Such employees' importance suggests that, in time, they will also need training in decision-making, negotiations, relationship management, and written communications.(1,2,3,4,5)

Transportation operators are also in the best position to understand the condition of the vehicle they operate, the electronic equipment in their vehicles, and whether or not all systems are working properly. Consequently, operators' training should extend far beyond how to turn the equipment on and off and how to steer. As is the case with any employee who operates any equipment, they should be well aware of the proper functioning of a correctly calibrated and maintained piece of equipment.(3)

Such awareness is never more critical than with vehicles such as over-the-road trucks, trains, tugs, barges, or airplanes. The consequences of vehicle failure are too great-to the smooth operation of the logistics system, and to life and limb. Operators also need training in company policies and procedures, training that should be routinely updated. Too many firms make changes while operating employees are gone and fail to keep them informed. (3)

Among the interpersonal skills training needs, anger management stands out for this job family. This assertion is not to suggest that anger management is not needed by others, but operating employees are more likely to find themselves in situations that may turn to physical hostility. They need to understand how to manage anger in themselves and others. (3)

\section{Motor Carrier Operating Employees Summary}

Motor carrier operating employees jobs involve operating complex equipment and interacting with a variety of employees in their own company and with customers and suppliers. These jobs are increasing in complexity and in training needs as more tasks are pushed to the operating level-the cab of the vehicle in these cases. The research supports the idea that these employees need training in areas that in the past were reserved for managers and supervisors: communications, interpersonal skills, and working with complex technology.

\section{Developing A Training Approach}

For logistics jobs, the primary training system is on-the-job experience, even for skills and knowledge regarded as critical to job performance. On-the-job experience is informal, uneven, and can foster poor work practices, inadequate job knowledge, and a limited range of job knowledge. On-the-job experience translates well to performing the job, if the content of the training is accurate and complete. Unfortunately for those firms that rely on this approach, the content is 
often inaccurate or incomplete. New employees learn shortcuts that defeat efficiency and effectiveness, undercut customer service, or create safety hazards.

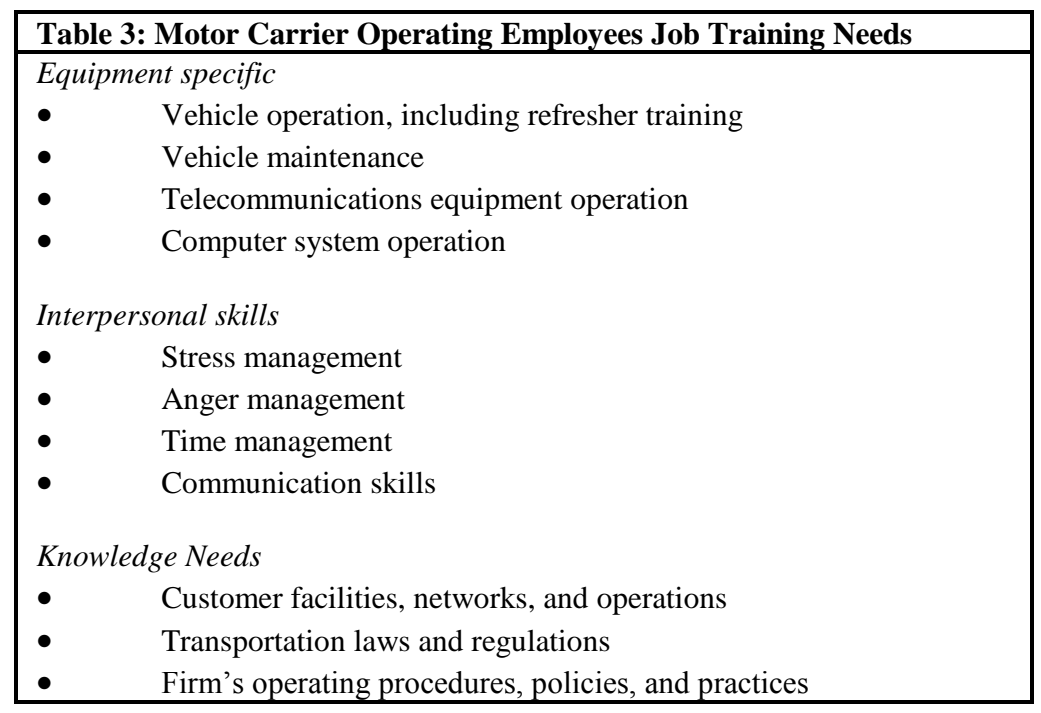

Ideally, each job family should have a coach who monitors employee performance, encourages good work behavior and discourages poor work behavior. A few firms have even renamed their supervisors and managers "coaches." This renaming process means little unless the "coach" is given the chance to spend enough time with each employee or member of each job family to know the training needs and prepare to meet them. Coaching is the most customized form of training. It offers immediacy and focus. Unfortunately, the ideal is difficult and widely regarded as too expensive. Below we review the key findings in the research as they pertain to developing an effective approach to training.

\section{A System Wide View}

The outstanding firms in the research used systematic training to build extraordinary logistics and manufacturing organizations. Two firms in the research have used comprehensive training programs for decades. Their performance has been outstanding all along. Their performance is sustained by relentless training, so no one ever falls behind.

These firms also followed a principle emphasized in this research: training should begin by developing a common, consistent view of the logistics system for all employees. The logistics organization has control over the information and people to put this principle into practice. Too many firms do not, meaning that employees at all levels perceive different logistics systems. A point of clarification-this does not mean that every employee should see the logistics system in the same way. A variety of perspectives can be valuable to the development and improvement of logistics systems. Rather employees should see the same system; they should work from a common set of facts about the system.

"We adopted a training system that helps us work from common ground. (A training firm) worked with a cross-section of our employees to create a picture of our logistics system, a physical picture, that we could share with every employee. You can see where every job fits in the picture. After we put together the picture, we worked with employees to create a list of competencies for each job. The competencies fit the picture." -Manufacturing Director of Logistics Training

Training goes beyond new employee orientation, although it certainly should be part of orientation. Often, long time employees lose sight of their role in the system as the system changes. If firms want adaptable, flexible employees, 
then they must maintain a concrete, fact based view of the system among those employees. Clearly, outside organizations will not provide the content for this type of training, although they may facilitate creating the common view.

Comprehensive training serves multiple purposes. First, it creates a foundation for other training. The organization can readily define training needs in terms of the system. Second, it eases communication. If all employees are discussing the same system, they will have fewer confused or confusing conversations. They speak the same language about the same issues if this kind of baseline training is performed. Third, training helps employees recognize the importance of the tasks they perform on the job.

\section{Focus on Communications and Interpersonal Skills}

A second important point arises in all of the best practices and outstanding logistics organizations: communications and interpersonal skills should be central themes in any logistics training system. Every logistics job involves interaction with other people, more so than many other jobs. Development of these skills requires a wide range of training topics; supervisory skills, time management, stress management, report writing, business writing, team building, training as trainers, and meeting skills are examples of crucial topics.

Training in supervisory skills helps supervisors maintain their skills and work with their subordinates better. It also prepares operating employees for promotion to supervisor. The same skills, applied in a different context, also apply to managers with supervisory responsibility. Firms often give this training to supervisors, managers, and operating employees who are in line for promotion.

Unfortunately, many logistics organizations are inconsistent in providing such training at the supervisory and operating levels. Not all firms provide supervisory training to managers, assuming that a college degree or job experience will suffice. In most degree programs, supervisory skills receive only cursory attention, if any, and job experience may as easily teach and reinforce bad supervisory practice as good. The best-practice organizations involved in this research made supervisory training available to employees early in their tenure with the firm and required it when promotion was imminent.

The need for team skills pervades many organizations, even those organized along traditional lines. Logistics work is collaborative by nature. It means working together, often in groups that form and reform routinely to direct attention to new projects and programs. One type of 3PL thrives on project oriented teams. Most logistics managers' career paths will in the future pass through a 3PL or a consulting firm in which team skills will be essential.

Operating employees may need training skills as much as managers. Training new employees should go beyond turning on the machine or entering data into the computer. Formal, structured training brings employees to competence more quickly than informal, casual training. Effective training is no accident. Just as data entry and customer service tasks have become ubiquitous, responsibility for training should be widespread in the organization. Furthermore, training effectiveness should become part of an employee's evaluation. Otherwise, if everyone is 'responsible," then "no one is responsible' may become the organizational reality.

\section{Impact of Flattening Organizations}

Training to develop managerial and supervisory skills should be offered to operating and support personnel. The flat organization dictates that operating and support personnel take on responsibilities once associated with management jobs. With warehouse workers entering data, driving forklifts, and taking customers on tours of the warehouse, they must now have computer, customer service, and machine operation skills. No part of their training should be neglected. One large organization, with over \$29 billion in revenue, now has only four layers in its multinational structure. When customers have problems with the firm's heavy-duty, industrial products, they call directly the employee who built the product.

Managers should bear in mind that training employees in managerial and supervisory skills will demystify these skills. Operating employees will have higher expectations of managers' application of those skills. Nonetheless, the new 
organizational structure and new logistics approaches force this training further down inside the organization. As span of control increases, managers will have less time to spend overseeing the work of each employee. It makes sense then to give the employees the skills the manager might have used.

\section{Training Sources and Partnerships}

The implications are that logistics managers should devote full time to training. That, of course, is impossible, so the development of training partnerships and relationships becomes very important. Where logistics managers play an important role, aside from assuming some training duties and assuring their own training, is in institutionalizing training in the organizational culture.

Training should be offered to employees through a variety of sources, including community colleges, universities, training firms, Web-based training, associations, and consulting firms. No one source is likely to provide everything, but properly blended, the training can become part of the work life of employees at all levels.

Training programs vary greatly in cost, time commitment, level of content, and instruction. As such, training programs and systems should be held accountable for their results. The results should be measured and the feedback should be used to improve the programs. Just as firms work closely with other suppliers to improve goods and other services, measurement programs should be used to help build stronger training partners, better training programs, and more effective training systems.

\section{Conclusion}

Changes in transportation jobs are driven by technology, economic conditions, and the nature of the workforce. Globalization, intermodalism, and off-shore manufacturing are all intimately connected and all influence the work of transportation. They underscore the need to train operating employees on communications and computer equipment, in interpersonal skills, and regulatory compliance; to find employees with these skills, or who can readily acquire them; and to find and train managers who can keep, develop, and train these employees-a need for supervisory skills that is daunting.

This has resulted in a lack of training and a lack of systematic development programs for logistics personnel in general and operating employees in particular. Coupled with the growing importance of operating personnel and the flattening of organizations, the shortage of well trained and skilled operating employees creates a dilemma for logistics managers and organizations. In light of these facts and resulting circumstances, the value of training is difficult to refute, but firms still tend not to make the investment. Training is expensive, time-consuming, and risky in the sense that the trained employee may leave, and in fact, probably will leave within five years. Nonetheless, training is worth it. The costs can be minimized by choosing the right source of training and the right content to suit each job and each person. This can be accomplished by creating a series of partnerships that benefit the logistics organization, the employees, and the training partners.

The problem is transmitting the knowledge to other employees who may need it and creating the common view of the logistics system already mentioned. If such knowledge transmission is successful, the final outcome will be a more satisfied and better performing organization from the operating employee to the key decision makers. The greatest danger lies in letting employees continue to operate at their current level and believe that what they do is of little consequence to the organization. 
Notes 